\title{
Does Applying Screenshot Annotations Enhance Learning Effectiveness? The Moderating Role of Course Difficulty
}

\author{
Travis K. Huang \\ Ling Tung University \\ travisk.huang@gmail.com
}

\author{
Eugenia Y. Huang \\ National Chengchi University \\ huang.eugenia@gmail.com
}

\begin{abstract}
The rapid growth of information technologies has given rise to a variety of e-learning platforms. However, simply providing multimedia instructional materials does not necessarily improve users' understanding of the instructional content. The study makes use of Flickr annotations, including stickers, drawings, and texts, to improve users' learning performance while learning computer software. All users are able to upload screenshots to Flickr to demonstrate computer software problems and troubleshooting software. To clarify what their screenshots mean, they can describe their problems or provide their opinions by attaching annotations to a specific screenshot. Through the use of annotations, Flickr provides the users with an easier way to describe or understand problems. This study comprised a three-course investigation. In addition to understand users' learning effectiveness, two context-related factors, peer opinion and personal innovativeness, were chosen as the basis for the research model. Based on data collected from 281 students, the results indicated that peer opinion had a positive effect on intention, whereas the effect of personal innovativeness, surprisingly, was negative rather than positive. Besides, the results based on the three computer software courses with different levels of difficulty confirmed the moderating effect of course difficulty.
\end{abstract}

\section{Introduction}

With the great advancements in educational technologies and instructional science, the latest information and communication technologies (ICTs) in conjunction with mobile devices have created a variety of innovative means to teaching and learning. Such technology-enhanced learning not only leads to active and ubiquitous leaning, but also promotes the generation of learning communities [1]. However, simply presenting information to students does not guarantee that learning will take place [2]. By increasing mutual interaction among users, e-learning has sufficient opportunities to simulate critical thinking and deeper processing of the subject matter [3]. In addition to providing course materials, e-learning systems nowadays enable students to interact with their classmates and teachers by means of discussion forums, chat rooms, instant messaging, or e-mail. As online discussions hold a promise for collaborative knowledge construction, increasing the degree of interactivity among learners becomes a major and growing player in a world of continuous learning [4]. Both teachers and learners alike need to embrace the latest ways to interact with people and course materials to enhance learning effectiveness.

Social-networking sites (SNS) have become the preferred forum for social interaction, and have made a great impact on knowledge sharing and learning performance by means of online discussion, content creation, file sharing, and entertainment [5]. Some social networking sites, such as Flickr and Facebook, furnish users with a highly interactive photo-sharing environment, which allows the user to create tags or annotations on a photo. This photo-sharing environment can be an innovative method for learners to demonstrate their problems by posting screenshots, rather than personal photos, when they encounter computer software difficulties [6]. In particular, Flickr provides its users with three types of annotationsstickers, drawings, and texts - to pinpoint the specific portion of the screenshot by means of the annotation tools, called photo editor, as shown in Figure 1. Every screenshot is unique and personalized after annotation. For example, as shown in Figure 2, a sticker annotation can be made by drawing a rectangle, adjusting its position and size, and entering text above a screenshot. Hence, software problems can be described more clearly than with text alone and can be solved with greater certainty.

This study was performed to make use of Flickr annotations to support computer software learning. When users encounter particular software problems, they may be confused and have difficulty describing their problem when they attempt to obtain help. By 


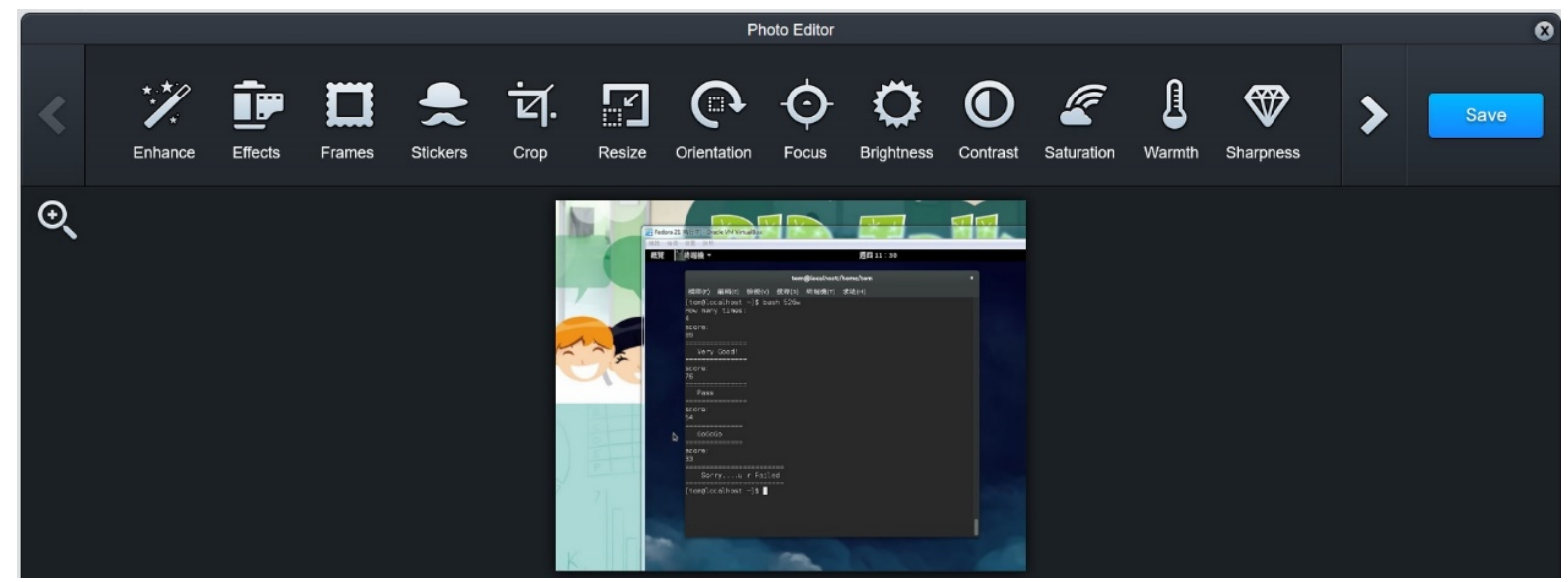

Figure 1. Annotation tools on Flickr

using screenshots, the acquisition of computer software skills could become easier and more efficient.

The emergence of social-networking media has increased connectivity within society. As people tend to rely heavily on peer-to-peer interaction, they have swiftly adopted the new media formats [7]. Students tend to embrace the new information technology, but does this use and enthusiasm translate into perceptions of increased learning effectiveness [2]? As the development of annotation systems matures, much research has proved their positive influence on users' learning performance [8] [9] [10] [11] [12] [13] [14]. Hence, not only users' intention to use Flickr screenshot annotations, but also their learning effectiveness were investigated in the study.

Course difficulty is positively associated with learning outcome and achievement [15][16]. Moreover, when it is difficult for students to earn high grade in a course, earning high grades plays a strong role in helping to produce high student evaluations [17].
Thus, course with higher level of difficulty may help to improve students' learning effectiveness by using Flickr screenshot annotations. This study thus examines the relationship between users' intention and learning effectiveness under different types of computer software. The moderating effect of course difficulty was examined. The study aims to investigate the effects of Flickr screenshot annotations in the context of computer software learning. A three-course investigation was conducted. The subjects of this study are undergraduates who are about to take computer software courses, and the information technology measured is Flickr screenshot annotations. In addition to understand users' learning effectiveness, two context-related factors, peer opinion and personal innovativeness, were chosen as the basis for the research model. Hence, this study intended to answer the following question: Does Flickr screenshot annotations enhance the users' understanding and improve learning effectiveness?

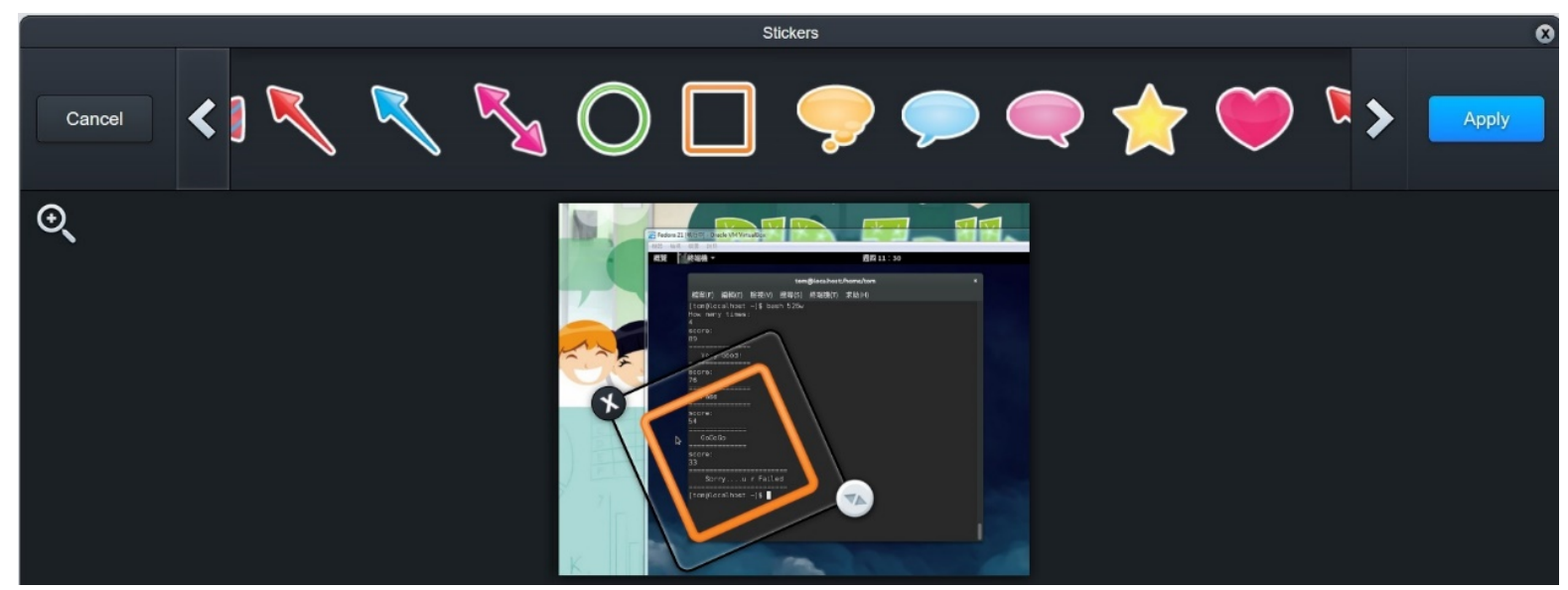

Figure 2. Creating a sticker annotation to a screenshot 
This study emphasizes the moderating role of course difficulty, making it a milestone in understanding the effectiveness of e-learning platforms. The results not only augment the theorization and application of screenshot annotation, but also offer insights into enhancing e-learning effectiveness.

\section{Literature review}

The rapid growth of information technologies has given rise to a variety of e-learning platforms. Most elearning platforms provide instructional materials for users that are presented through various types of media, such as text, image, audio, animation, and video. However, simply providing multimedia instructional materials does not necessarily improve users' understanding of the instructional content [18]. Because the instructional content often contains high levels of equivocality and uncertainty, the instructional materials are increasingly being supplemented with discussions and interaction among users to help them comprehend the content. Hence, e-learning platforms should provide effective ways of not only presenting the instructional materials, but also enhancing understanding through the interaction between the users.

According to media richness theory [19][20], task performance is greatly improved when the task requirements match the richness of the medium. The use of the appropriate media enables users to communicate clearly, convey information easily, rapidly acquire shared meaning and knowledge, and thereby enhance their understanding. However, synchronous media may not be the "richest" form of communication, as the richness largely depends on the context [21]. In this study, we applied Flickr annotations as a supplement to the discussion forum. During the semester course, users were able to use Flickr annotations to hand in homework and to explain their problems for troubleshooting. We found that asynchronous media were more effective than synchronous media.

As most e-learning systems place greater emphasis on information than communication, Hamuy and Galaz [11] proposed a course management system to enhance learning through interaction in a virtual environment. They further suggested that e-learning systems should provide students with sufficient opportunities for information interaction and communication interaction if the aim is to enhance students' learning performance. Schellens and Valcke [22] found that students in discussion groups are very task-oriented, and that asynchronous discussion systems can result in higher levels of knowledge construction. Thus, the inclusion of a discussion environment in an e-learning system can increase students' learning. For example, Jeong and Joung [10] proposed an asynchronous onlinediscussion system that uses message constraints and labels, which are helpful for identifying critiques and post arguments. Nonetheless, most bulletin post systems and even the discussion forums in annotation systems are in textual format and do not use richer media. However, argumentative diagram tools, which exhibit greater richness, are much more useful than text-outline tools in helping users discuss difficult problems [23].

\subsection{Annotation systems}

Increasing numbers of e-learning platforms are using text annotation functions, such as the Web 2.0 annotation system MyNote [24] and the social annotation tool Diigo [25]. These annotation systems are useful for peer critiques [26], discussions, and brainstorming. However, these annotation systems focus on online materials such as static web pages and documents. As the degree of task or course difficulty increases, text annotation may not be "rich" enough to enable learners to solve problems. Thus, other types of annotations with higher levels of media richness need to be considered.

In this study, we used Flickr annotations to improve users' learning performance while learning computer software. Flickr is a photo-sharing platform that allows three types of annotations to be added to a specific photo, namely, stickers, drawings, and texts. All users are able to upload screenshots to Flickr. To clarify what their screenshots mean, they can describe their problems or provide their opinions by attaching annotations to a specific screenshot. Others can continue to communicate about the specific screenshot by leaving comments in the section below the screenshot. Thus, through the use of annotations, such as stickers, drawings, and texts, Flickr provides the users of e-learning platforms with an easier way to describe or understand problems than the solely text based systems. Furthermore, in computer software learning, users often encounter unpredictable problems that they are unable to describe clearly. Hence, according to media richness theory, the screenshot annotations on Flickr can provide higher levels of richness and thus overcome the abovementioned difficulties. In this study, screenshots were treated as boundary objects that could establish common meaning and in turn enhance the efficiency of the communication between users [27] [28]. 


\subsection{Learning effectiveness}

Annotation systems have been shown to significantly improve learning performance. For example, VPen, a web-based annotation system, successfully increased learners' interest and learning performance by promoting interaction between learners [9]. A personalized annotation management system (PAMS) was found to be useful for conducting learning tasks [12]. A web-based collaborative annotation system, called Hy-Lighter, was also found to not only improve students' learning comprehension and outcome achievement, but also increased the students' engagement, reading comprehension, and meta-cognitive skills [14].

Our main research question is do the screenshot annotations on Flickr enhance learners' understanding and improve learning effectiveness? The dependent variable is learning effectiveness. When assessing elearning effectiveness, we need to consider not only the actual effectiveness of the learning content, but also the perceived effectiveness of the e-learning system [29] because the degree of satisfaction with the learning achievement in on-line courses is a critical factor in determining learning effectiveness [30]. In addition, Lowerison, Sclater, Schmid, and Abrami [2] suggested that positive learning experiences include the users' feeling that they have effectively interacted with the instructor and other students, and that the users feel in control of their own learning by means of their active participation. Hence, to measure learning effectiveness, we evaluate students' perceived satisfaction with their learning experiences.

\subsection{Intention and learning effectiveness}

Over the past two decades, the technology acceptance model (TAM) has successfully explained the adoption of new information technology [31] [32], and consistently predicted about $40 \%$ of the variance in users' intentions to use information technology and actual usage [33]. The TAM adopts the premise that users' behavioral intentions regarding information technology determines their actual usage behavior [34]. The research context of this study is computer software learning, and the information technology that is measured is the screenshot annotations on Flickr. Thus, it is necessary to clarify the relationship between learners' intentions to use the Flickr screenshot annotations and their learning effectiveness.

The use of social annotation tools has significantly promoted learners' intentions to read online materials [14]. Students tend to value the use of new information technology for learning [2] [35]. As Barak and
Levenberg [36] stated, learners with flexible thinking had higher level of acceptance of new or changing technologies, and thus adapted to changes in learning situations. Therefore, if users have a greater intention to participate in the screenshot annotations on Flickr, their learning effectiveness will be improved. Based on the foregoing reasoning, we propose the following hypothesis.

Hypothesis 1: The greater the users' intention to use screenshot annotations, the greater their learning effectiveness.

\subsection{Peer opinion}

Lewis, Agarwal, and Sambamurthy [37] found that knowledge workers desired social companionship and tended to concur with their colleagues' opinions on the adoption of new information technology. Colleague opinion has been shown to have a normative influence on knowledge workers. For instance, Kim and Kankanhalli [38] found that favorable colleague opinion had a negative effect on user resistance. In contrast, we expect that colleague opinion will have a positive influence on users' willingness to adopt a new information technology.

Kim and Kankanhalli [38] treated colleague opinion as a kind of subjective norm, which has previously been identified as an antecedent of the TAM [39]. As active participants usually have a positive attitude toward social annotation systems [13], their positive opinion is likely to influence their peers. Thus, we included peer opinion as an antecedent of intention in this study because it may affect users' behavioral intentions with regard to the adoption of Flickr screenshot annotations. Based on this reasoning, we propose the following hypothesis.

Hypothesis 2: The higher the level of positive peer opinion, the greater the users' intention to use Flickr screenshot annotations.

\subsection{Personal innovativeness}

It is important to investigate the factors that affect the use of an innovation after it becomes available to the wider population [40]. Hirshman [41] found that people with stronger novelty-seeking motives may demonstrate greater willingness to adopt an innovation. In addition to examining the relationship between personal computer adoption and the user's need for innovativeness [42], Lin [43] further verified the relationship between the use of webcasting and user innovativeness, which he termed "personal 


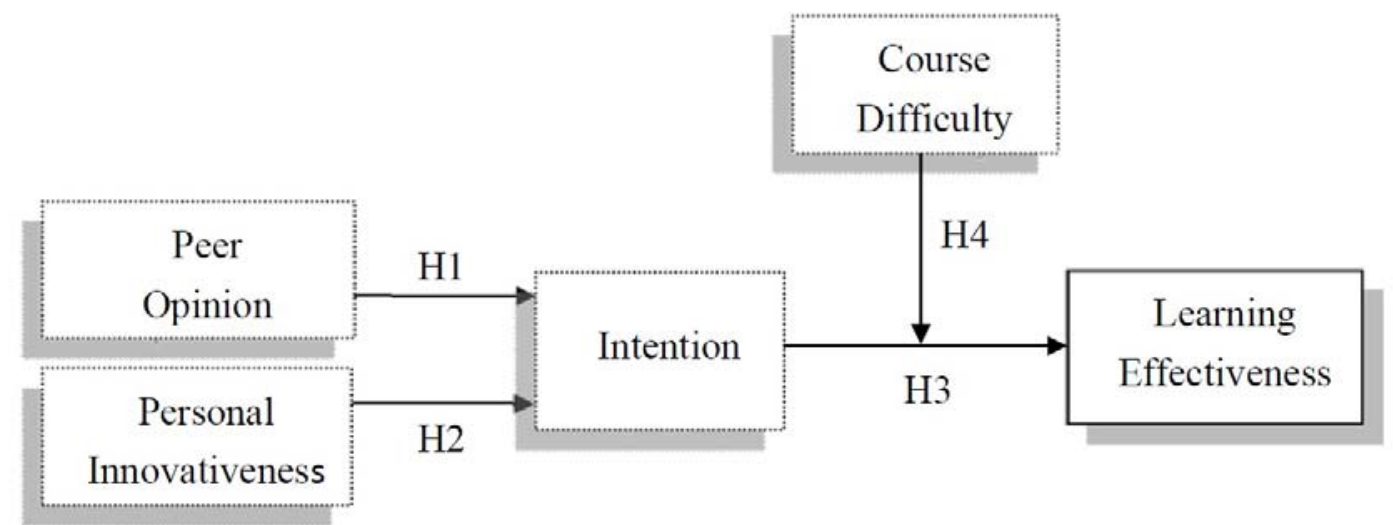

Figure 3. Research model

innovativeness." He found that once people begin to actualize their need for innovativeness, they must search for and keep up with innovative ideas [42]. This phenomenon reflects people's desire for innovativeness. According to diffusion of innovation theory (DIT) and the findings of related research, personal innovativeness is an important antecedent of users' intentions to use a new-technology. Based on the abovementioned reasoning, in this study, we investigate the effect of users' personal innovativeness on their behavioral intention to use Flickr screenshot annotations. We propose the following hypothesis.

Hypothesis 3: The higher the level of users' personal innovativeness, the greater their intention to use Flickr screenshot annotations.

\subsection{Moderating role of course difficulty}

Task difficulty has been found to have significant effects on organizational learning performance [44][45]. Task difficulty clearly involves numerous factors. The factor that is most relevant to our context of computer software learning is course difficulty, which has been shown to be positively associated with learning outcomes and achievement within student groups [46] [47]. Tucker, Jones, Mandy, and Gupta [47] found that although students perceived a higher degree of course difficulty, they spent more time learning the subject by trying to figure out the puzzles they encountered, which led to greater levels of academic stress. In this regard, more difficult courses are likely to affect students' learning outcomes. For instance, when students have difficulty earning high grades in a course, earning high grades plays a strong role in helping to produce high student evaluations [17]. Therefore, courses with higher levels of difficulty may help to improve students' learning effectiveness when using Flickr screenshot annotations. Thus, we examine the relationship between users' intentions and learning effectiveness under different types of computer software.

Course difficulty is the degree of difficulty of the subject matter being taught. In this study, the subject matter comprises three types of computer software, namely, Linux Fedora, Linux servers, and freeware applications. When users learn different types of computer software, they encounter problems that have different levels of equivocality and uncertainty. Thus, we expect that when users learn more difficult computer software, they will be more likely to exhibit their problems by using the screenshot annotations on Flickr and, as a result, will demonstrate a higher degree of learning effectiveness. This leads to the following hypothesis.

Hypothesis 4: The higher the level of course difficulty, the stronger the relationship between users' intention and learning effectiveness.

We measured the effects of peer opinion and users' personal innovativeness on users' intention. In addition to examining the direct effect of users' intention to use Flickr screenshot annotations on their perceived learning effectiveness, we examined the moderating effect of course difficulty on the relationship between users' intention and learning effectiveness. The research model is summarized in Figure 3.

\section{Research method}

As the context of the study is computer software learning, the type of software used is a significant factor. Moreover, students' prior experience with computer software will influence their perception of the difficulty of learning the same computer software. 
Table 1. Three-course experiment

\begin{tabular}{lccc}
\hline & The first course & The second course & The third course \\
\hline Course & Linux Fedora & Linux servers & Freeware applications \\
Time interval & $2014 / 9-2015 / 01$ & $2015 / 2-2015 / 06$ & $2015 / 9-2016 / 01$ \\
Number of Subjects & 125 & 73 & 91 \\
\hline
\end{tabular}

However, the percentage of students who consider a specific type of software to be difficult increases as the difficulty of the software increases. In other words, more students will encounter difficulties in learning a difficult type of software than in learning an easier one. To comprehensively assess the effect of applying Flickr screenshot annotations to computer software learning, the software taught should include both easy and difficult examples. Thus, this study was conducted in three courses. Flickr was introduced to the students in three different courses over two years. The difficulty of each course varied. Students learned to use a different software application with annotating images in Flickr in each course. As shown in Table 1, a series of experiments were carried out under the research setting using target courses focusing on Linux Fedora, Linux servers, and freeware applications. Out of the three applications, the most difficult application for students was expected to be Linux servers. Data from students who had previously taken the other courses in the research study were not included in the subsequent study. As the difficulty of the subject matter being taught ranged from easy to difficult, we were able to evaluate the course difficulty with greater confidence. In addition, the subjects of the study were 289 undergraduates majoring in management information systems. The participants enrolled in one of the three target courses, which were taught in three different semesters.

As a major part of the course requirement, the students were required to hand in their homework to Flickr and describe their problems by using Flickr annotations. To control the frequency of the students' Flickr use, five pieces of homework were assigned in each course. However, all of the students were encouraged to propose problems regarding their homework or software learning on Flickr. Each homework assignment or problem could be expressed in screenshot format. Specifically, the students were able to upload screenshots to Flickr and were encouraged to respond to all of the screenshots. Thus, the students were able to demonstrate their homework and problems more vividly and clearly by using the various types of annotations above specific screenshots, and were able to discuss or share their opinions by leaving comments in the section below a specific screenshot. If the students appreciated any annotated screenshot, they could "like" it by clicking the adjacent "fave" icon. By doing so, the students were able to
To investigate the effects of Flickr screenshot annotations on computer software learning, questionnaires were administered to 289 students, who enrolled in one of the target courses taught over the three semesters. The students were aware that they were involved in a project, but were blinded to the research hypotheses.

A questionnaire survey was administered to measure the students' intention to use Flickr screenshot annotations, peer opinion, personal innovativeness, perceived learning effectiveness, and course difficulty when using Flickr screenshot annotations to demonstrate their problems in learning specific types of computer software. The research model shown in Figure 3 was tested using the survey data accumulated during the three-stage data collection process.

The independent variables in this study were students' intention, peer opinion, and their personal innovativeness, whereas the dependent variable was learning effectiveness. In addition, the moderating variable was course difficulty. These five variables were measured on a seven-point Likert scale ranging from 1 "strongly disagree" to 7 "strongly agree." The measurement of each construct is described as follows. Intention. The items of intention (three items) were adapted from Ajzen and Fishbein's scale [48] with modifications to measure students' intention to apply screenshot annotations on Flickr. The scale has been confirmed as having high levels of flexibility, reliability, and generalizability in a number of studies. The Cronbach's $\alpha$ for this three-item measure was .952 . Personal innovativeness. We used the scale developed by Lin [43] to assess users' personal innovativeness, which is defined as the users' desire for innovative ideas or products. The scale contains four items, which focus mainly on measuring the degree of an individual's interest and involvement in keeping up with the knowledge of innovative ideas or products. The Cronbach's $\alpha$ for this four-item measure was .974.

Peer opinion. Kim and Kankanhalli [38] developed a scale to assess colleague opinion as perceived by users. The scale comprises three items, which we used to measure the degree of classmates' positive opinion toward the use of screenshot annotations on Flickr. The Cronbach's $\alpha$ for this three-item measure was .916.

Learning effectiveness. We measured learning effectiveness by the students' perceived satisfaction with their learning experiences, as measured on a 7item scale [2]. The students were asked to indicate the 
Table 2. Correlations between variables

\begin{tabular}{llllll}
\hline & 1 & 2 & 3 & 4 & 5 \\
\hline 1. Peer opinion & 1 & & & & \\
2. Personal innovativeness & $.589^{* *}$ & 1 & & & \\
3. Intention & $.773^{* *}$ & $.647^{* *}$ & 1 & & \\
4. Course difficulty & $-.686^{* *}$ & $-.543^{\star *}$ & $-.622^{* *}$ & 1 & \\
5. Learning effectiveness & $.757^{* *}$ & $.671^{* *}$ & $.735^{* *}$ & $-.591^{* *}$ & 1 \\
\hline \multicolumn{1}{c}{ Note. ${ }^{*} \mathrm{p}<.05 .{ }^{* *} \mathrm{p}<.01}$. & & & &
\end{tabular}

effectiveness of the screenshot-annotation system used in the course. The Cronbach's $\alpha$ for this seven-item measure was .976 .

Course Difficulty. Addison, Best, and Warrington [17] developed a course experience questionnaire (CEQ) that uses 10 items to measure students' perceived course difficulty and instructor evaluation. We adapted three items from the CEQ to measure course difficulty. Each course focused on a specific type of computer software, namely, Linux Fedora, Linux servers, and freeware applications. In addition to the varying difficulty of each course, the students had varying levels of personal software experience and prior knowledge. Thus, course difficulty was measured by the students' perceptions of the courses in which they were enrolled. The Cronbach's $\alpha$ for the three-item measure was .960 .

\section{Results}

\subsection{Data analysis}

Of the 289 students attending the classes, 281 completed the questionnaires, giving a response rate of $97.2 \%$. The correlations between the variables were tested using Pearson's correlation coefficient. As shown in Table 2, all of the variables were significantly interrelated. Peer opinion, personal innovativeness, intention, and learning effectiveness were positively correlated with each other, while course difficulty was negatively correlated the other four variables. Peer opinion and personal innovativeness were also found to be positively correlated with learning effectiveness. Although these relationships were not examined in this study, the results provide interesting cues for future exploration. However, correlation does not imply causation. Thus, we further examined the causal relationships between the variables by means of structural equation modeling.

\subsection{Structural model}

Using the 281 records, the proposed model was assessed with maximum likelihood estimation using AMOS. All of the calculations were based on the covariance matrix of the variables. Four common model-fit measures were used to assess the model's overall goodness of fit, the ratio of $\chi 2$ to the degrees of freedom (CMIN/DF), adjusted goodness-of-fit index (AGFI), comparative fit index (CFI), and root mean square error of approximation (RMSEA).

The results indicated that the proposed model $(\mathrm{CMIN} / \mathrm{DF}=2.333 ; \mathrm{AGFI}=.837$; $\mathrm{CFI}=.971$; RMSEA $=.069$ ) had a good fit, because the values for all of the criteria were better than the recommended values (CMIN/DF < 3; AGFI > .80; CFI > .95; RMSEA $<.08$ ). Thus, we used the model to examine our hypotheses.

As shown in Figure 4, the standardized path coefficient from peer opinion to intention was positive, and the relationship was statistically significant. Thus, Hypothesis 2 was supported. Although the path running from personal innovativeness to intention was statistically significant, the standardized path coefficient was negative rather than positive. Thus, Hypothesis 3 was not supported.

The relationship between intention and learning effectiveness was statistically significant with a positive standardized path coefficient, confirming Hypothesis 1. Through its direct effects on intention, peer opinion affected learning effectiveness indirectly and positively, whereas personal innovativeness had a negative rather than positive indirect effect on learning effectiveness. The $\mathrm{R}^{2}$ value indicated that $75 \%$ of the variance in users' learning effectiveness was explained by the course difficulty and their intention.

Although both intention and course difficulty were found to have direct positive effects on learning effectiveness, the effect of the interaction between intention and course difficulty on learning effectiveness was significantly negative. Thus, the moderating effect of course difficulty was confirmed. Hypothesis 4 was supported.

Course difficulty was shown to moderate the relationship between intention and learning effectiveness. This interaction effect is illustrated in Figure 5. When the students perceived relatively 


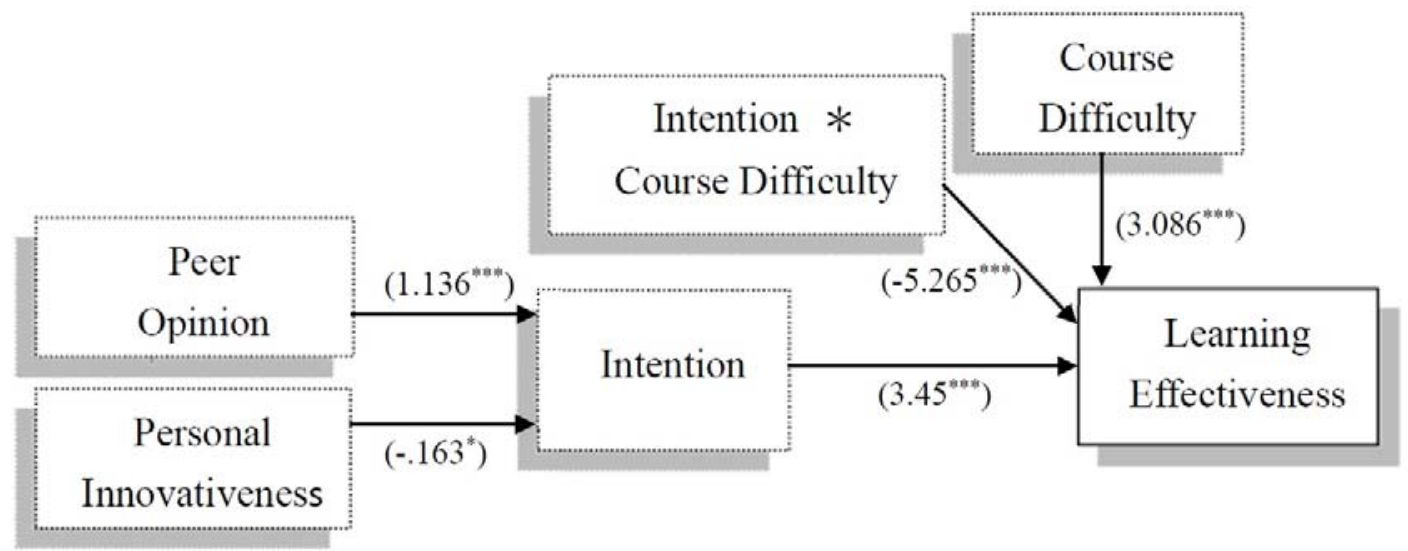

Figure 4. Standardized path coefficients of the proposed model

greater course difficulty, their intention had a strong and positive effect on learning effectiveness. However, when the degree of course difficulty was relatively low, the students' intention still had a strong and positive effect on learning effectiveness. However, the learning effectiveness of high-intention students in the highdifficulty course was better than the low-intention students' learning effectiveness in the low-difficulty course.

An important practical implication of these findings is that students' learning effectiveness may be significantly enhanced by enhancing their intention to apply screenshot annotations on Flickr while learning computer software, regardless of whether the perceived course difficulty is low or high. The results of this study show that Flickr screenshot annotations are not only a convenient way to supplement computer software learning, but are also a useful means for students to interact with each other for troubleshooting.

\section{Conclusion}

In this study, the screenshot annotations on Flickr, which include stickers, drawings, and texts, were used to enhance students' learning effectiveness while learning computer software in three target courses. We empirically examined the effects of students' personal innovativeness and peer opinion on their intention, and the moderating effect of course difficulty on the relationship between intention and learning effectiveness.

The results showed that the students' intention had a positive influence on their learning effectiveness. The Flickr screenshot annotations were also found to increase the students' intention, thereby shedding light on the process of enhancing students' learning effectiveness.

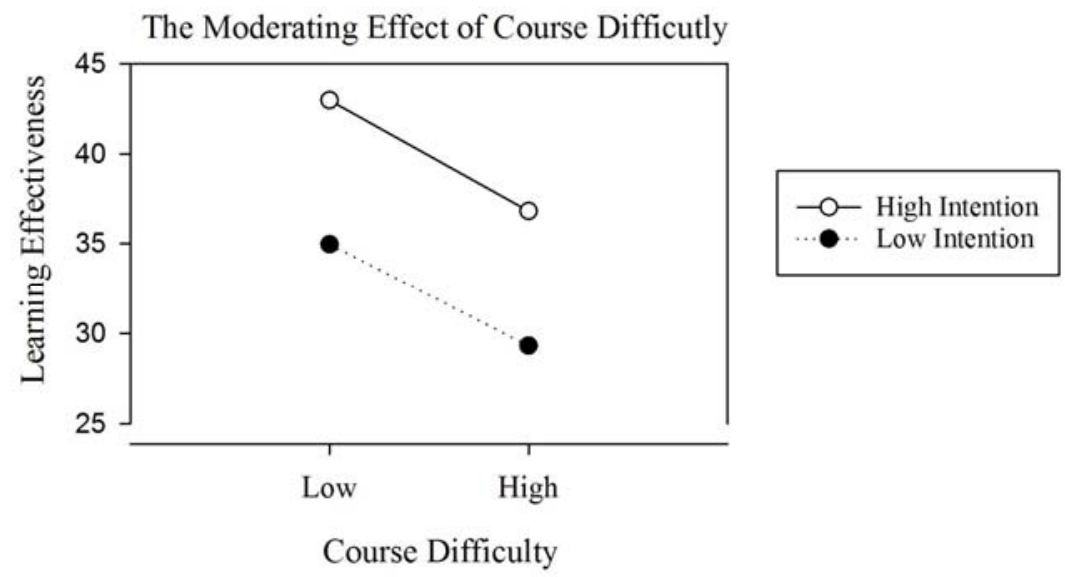

Figure 5. Moderating effect of course difficulty 
Moreover, peer opinion and students' personal innovativeness were identified as antecedents of their intention to use the Flickr screenshot annotations. Although peer opinion had a positive effect on intention, personal innovativeness, surprisingly, had a negative rather than positive effect. Hence, this study suggests that the most efficient means of enhancing students' learning effectiveness is to boost their intention by directing positive peer opinion toward the use of Flickr screenshot annotations, which can facilitate more practice and cooperative troubleshooting.

Furthermore, course difficulty was found to moderate the relationship between intention and learning effectiveness, which was positive when the degree of course difficulty crossed a specific threshold. The relationship between intention and learning effectiveness was closely linked to the subject being taught. The results based on the three computer software courses with different levels of difficulty confirmed the moderating effect of course difficulty.

The findings of this study contribute to the development of theories concerning the effect of course difficulty on learning effectiveness. A specific type of e-learning platform is not necessary for all courses. With respect to determining what kind of course is suitable for a platform, our results suggest that it is more appropriate to consider students' perceived course difficulty in advance. This study also contributes to the learning effectiveness research by showing that learning effectiveness can be enhanced by promoting positive peer opinion in computer software courses. As the results indicate, the students' greater intention led to better learning effectiveness. Therefore, teachers should concentrate on devising strategies to encourage students to share their positive experiences when using Flickr screenshot annotations to strengthen the peer opinion.

\section{Acknowledgments}

This research is partially supported by Ministry of Science Technology in Taiwan under project number MOST-103-2410-H-275-006-MY2.

\section{References}

[1] C. Plesch, C. Kaendler, N. Rummel, M. Wiedmann, and H. Spada, "Identifying Areas of Tension in the field of technology-enhanced learning: Results of an international Delphi study", Computers \& Education, 65, 2013, pp. 92-105. [2] G. Lowerison, J. Sclater, R. F. Schmid, and P. C. Abrami, "Student perceived effectiveness of computer technology use in post-secondary classrooms", Computers \& Education, 47, 2006, pp.465-489.
[3] B. Slof, D. Nijdam, and J. Janssen, "Do interpersonal skills and interpersonal perceptions predict student learning in CSCL-environments"? Computers \& Education, 97, 2016, pp. $49-60$.

[4] C. Kent, E. Laslo, and S. Rafaeli, "Interactivity in online discussions and learning outcomes", Computers \& Education, 97, 2016, pp.116-128.

[5] M. I. Eid, and I. M. Al-Jabri, "Social networking, knowledge sharing, and student learning: The case of university students", Computers \& Education, 99, 2016, pp. 14-27.

[6] T. K. Huang, "Exploring the antecedents of screenshotbased interactions in the context of advanced computer software learning", Computers \& Education, 80, 2015, pp. 95-107.

[7] A. Dickinger, M. Arami, and D. Meyer, "The role of perceived enjoyment and social norm in the adoption of technology with network externalities", European Journal of Information Systems, 17, 2008, pp. 4-11.

[8] T. Schellens, and M. Valcke, "Fostering knowledge construction in university students through asynchronous discussion groups", Computers \& Education, 46, 2006, pp. 349-370.

[9] W. Y. Hwang, C. Y. Wang, and M. Sharples, "A study of multimedia annotation of Web-based materials", Computers \& Education, 48, 2007, pp. 680-699.

[10] A. Jeong, and S. Joung, "Scaffolding collaborative argumentation in asynchronous discussions with message constraints and message labels", Computers \& Education, 48, 2007, pp. 427-445.

[11] E. Hamuy, and M. Galaz, "Information versus communication in course management system participation", Computers \& Education, 54, 2010, pp. 169-177.

[12] A. Y. S. Su, S. J. H. Yang, W. Y. Hwang, and J. Zhang, "A Web 2.0-based collaborative annotation system for enhancing knowledge sharing in collaborative learning environments", Computers \& Education, 55, 2010, pp. 752766.

[13] R. D. Samuel, C. Kim, and T. E. Johnson, "A study of a social annotation modeling learning system", Journal of Educational Computing Research, 45(1), 2011, pp. 117-137.

[14] S. Razon, J. Turner, T. E Johnson, G. Arsal, and G. Tenenbaum, "Effects of a collaborative annotation method on students' learning and learning-related motivation and affect", Computers in Human Behavior, 28, 2012, pp. 350-359.

[15] S. Zainudin, K. Ahmad, N. M. Ali, and N. F. A. Zainal, "Determining course outcomes achievement through examination difficulty index measurement", Procedia Social and Behavioral Sciences, 59, 2012, pp. 270-276.

[16] B. Tucker, S. Jones, A. Mandy, and R. Gupta, "Physiotherapy students' sources of stress, perceived course difficulty, and paid employment: Comparison between Western Australia and United Kingdom", Physiotherapy Theory and Practice, 22(6), 2006, pp. 317-328.

[17] W. E. Addison, J. Best, and J. D. Warrington, "Students' perceptions of course difficulty and their ratings of the instructor", College student Journal, 40(2), 2006, pp. 409-416. [18] R. A. Bartscha, and K. M. Cobern, "Effectiveness of powerpoint presentations in lectures", Computers \& Education, 41, 2003, pp. 77-86. 
[19] R. L. Daft, and R. H. Lengel, "Organizational information requirements, media richness and structural design", Management Science, 32(5), 1986, pp. 554-571.

[20] R. L. Daft, R. H. Lengel, and L. K. Trevino, "Message equivocality, media selection and manager performance: Implications for information systems", MIS Quarterly, 11, 1987, pp. 355-366.

[21] A. R. Dennis, and J. S. Valacich, "Rethinking media richness: Towards a theory of media synchronicity", In Proceedings of the 32nd Annual Hawaii International Conference on System Sciences, 1999.

[22] T. Schellens, and M. Valcke, "Fostering knowledge construction in university students through asynchronous discussion groups", Computers \& Education, 46, 2006, pp. 349-370.

[23] L. Munneke, J. Andriessen, G. Kanselaar, and P. Kirschner, "Supporting interactive argumentation: Influence of representational tools on discussing a wicked problem", Computers in Human Behavior, 23, 2007, pp. 1072-1088.

[24] Y. C. Chen, R. H. Hwang, and C. Y. Wang, "Development and evaluation of a Web 2.0 annotation system as a learning tool in an e-learning environment", Computers \& Education, 58, 2012, pp. 1094-1105.

[25] F. Gao, "A case study of using a social annotation tool to support collaboratively learning", Internet and Higher Education, 17, 2013, pp. 76-83.

[26] G. Mendenhall, and P. C. Johnson, "Fostering the development of critical thinking skills, and reading comprehension of undergraduates using a Web 2.0 tool coupled with a learning system", Interactive Learning Environments, 18(3), 2010, pp. 263-276.

[27] S. L. Star, and J. R. Griesemer, "Institutional ecology, "translations," and boundary objects: Amateurs and professionals in Berkeley's museum of vertebrate zoology, 1907-39", Social Studies of Science, 19, 1989, pp. 387-420.

[28] E. Y. Huang, and T. K. Huang, "Exploring the effect of boundary objects on knowledge interaction", Decision Support Systems, 56, 2013, pp. 140-147.

[29] R. P. Bostrom, L. Olfman, and M. K. Sein, "The importance of learning style in end-user training", MIS Quarterly, 14(1), 1990, pp. 101-119.

[30] R. H. Maki, W. S. Maki, M. Patterson, and P. D. Whittaker, "Evaluation of a web-based introductory psychology course: I. learning and satisfaction in on-line versus lecture courses", Behavior Research Methods of Instruments and Computers, 32(2), 2000, pp. 230-239.

[31] J. Yu, I. Ha, and M. Choi, "The technology acceptance model: Its past and its future in health care", Information \& Management, 42(7), 2005, pp. 965-976.

[32] A. Dickinger, M. Arami, and D. Meyer, "The role of perceived enjoyment and social norm in the adoption of technology with network externalities", European Journal of Information Systems, 17, 2008, pp. 4-11.

[33] V. Venkatesh, and H. Bala, "Technology acceptance model 3 and a research agenda on interventions", Decision Science, 39(2), 2008, pp. 273-315.
[34] F. D. Davis, R. P. Bagozzi, and P. R. Warshaw, "User acceptance of computer technology: A comparison of two theoretical models", Management Science, 35(8), 1989, pp. 982-1003.

[35] Y. M. Huang, Y. T. Lin, and S. C. Cheng, "Effectiveness of a mobile plant learning system in a science curriculum in Taiwanese elementary education", Computers \& Education, 54, 2010, pp. 47-58.

[36] M. Barak, and A. Levenberg, "Flexible thinking in learning: An individual differences measure for learning in technology-enhanced environments", Computers \& Education, 99, 2016, pp. 39-52.

[37] W. Lewis, R. Agarwal, and V. Sambamurthy, "Sources of influence on beliefs about information technology use: An empirical study of knowledge workers", MIS Quarterly, 27(4), 2003, pp. 657-678.

[38] H. W. Kim, and A. Kankanhalli, "Investigating user resistance to change in IS implementation: A status quo bias perspective", MIS Quarterly, 33(3), 2009, pp. 567-582.

[39] V. Venkatesh, and F. D. Davis, "A theoretical extension of the technology acceptance model: four longitudinal field studies", Management Science, 46(2), 2000, pp. 186-204.

[40] R. Busselle, J. Reagan, B. Pinkleton, and K. Jackson, "Factors affecting internet use in a saturated-access population", Telematics and Informatics, 16(1-2), 1999, pp. 45-58.

[41] E. C. Hirschman, "Innovativeness, novelty seeking, and consumer creativity", Journal of Consumer Research, 7(3), 1980, pp. 283-295.

[42] C. A. Lin, "Exploring personal computer adoption dynamics", Journal of Broadcasting \& Electronic Media, 42(1), 1998, pp. 95-112.

[43] C. A. Lin, "Webcasting adoption: Technology fluidity, user innovativeness and media substitution", Journal of Broadcasting \& Electronic Media, 48(3), 2004, pp. 446-465.

[44] T. Barmby, B. Eberth, and A. Ma, "Incentives, learning, task difficulty, and the Peter Principle: Interpreting individual output changes in an organisational hierarchy", Labour Economics, 19, 2012, pp. 76-81.

[45] S. K. Gardiner, D. F. Bjorklund, M. L. Greif, and S. K. Gray, "Choosing and using tools: Prior experience and task difficulty influence preschoolers' tool-use strategies", Cognitive Development, 27, 2012, pp. 240-254.

[46] S. Zainudin, K. Ahmad, N. M. Ali, and N. F. A. Zainal, "Determining course outcomes achievement through examination difficulty index measurement", Procedia Social and Behavioral Sciences, 59, 2012, pp. 270-276.

[47] B. Tucker, S. Jones, A. Mandy, and R. Gupta, "Physiotherapy students'sources of stress, perceived course difficulty, and paid employment: Comparison between Western Australia and United Kingdom", Physiotherapy Theory and Practice, 22(6), 2006, pp. 317-328.

[48] I. Ajzen, and M. Fishbein, Understanding attitudes and predicting social behavior, Prentice-Hall, New Jersey, 1980. 